FINAL TECHNICAL REPORT

\title{
RADIATION DAMAGE OF TRANSITION METAL CARBIDES
}

\author{
U. S. DEPARTMENT OF ENERGY \\ CONTRACT NUMBER DE-FG05-88ER48344
}

\author{
Principal Investigator \\ George Dixon
}

\author{
Department of Physics \\ Oklahoma State University \\ Stillwater, OK 74078
}

\section{DISCLAIMER}

\begin{abstract}
Discher of the United States This report was prepared as an account of work sponsored by an agency of the nor any of their Government. Neither the United States Government nor any agency legal liability or responsiemployees, makes any warranty, express or implied, or ass information, apparatus, product, or bility for the accuracy, completeness, or usefulness of any inge privately owned rights. Refer-

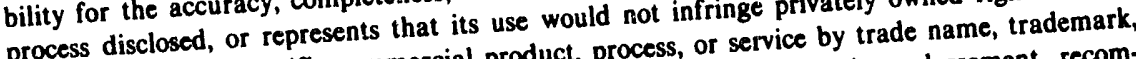
process disclosed, or recific commercial product, process, or service by trade endorsement, recomence herein to any specific commen necessarily constitute or imply its endorsement, re views manufacturer, or otherwise doe United States Government or any agency thereor. The ve the mendation, or favoring by the United state not necessarily state or reflect those of the and opinions of authors expressed herein do
\end{abstract}




\section{SUMMARY}

In this grant period we have investigated the electrical properties of transition metal carbides and the radiation-induced defects that are produced by low-temperature electron irradiation in them. Special attention has been given to the composition $\mathrm{VC}_{0.88}$ in which the vacancies on the carbon sublattice of this fcc crystal order to produce a $\mathrm{V}_{8} \mathrm{C}_{7}$ superlattice. The existence of this superlattice structure was found to make the crystal somewhat resistant to radiation damage at low doses and/or at ambient temperature. At larger doses significant changes in the resistivity are produced. Interesting annealing effects were observed which we believe to be connected with the reconstitution of the superlattice structure.

A portion of the results reported here were carried out in collaboration with F. A. Modine and C. B. Finch of Oak Ridge National Laboratory.

In the following sections we shall describe experiments on unirradiated carbides carried out in this study, and then turn our attention to the radiation effects, the results and their interpretation, and the impact of this project on human resource development in the field. 
ELECTRICAL PROPERIES OF TRANSITION METAL CARBIDES

\section{INTRODUCTION}

Few systematic studies have been made of the electrical properies of transition-metal carbide single crjistals over a wide temperature range. Hence, there is little basis for theoretical interpretations of the electronic transpon. Numerous studies of electrical properies of transitionmetal carbides have been reponed. ${ }^{1-11}$ However, most of these studies have yielded incomplete or uncerain results for the following reasons: (1) the measurements were often restricted to near ambient temperature; (2) polycrystalline samples, which require uncenain corrections for their porosity, were usually measured; and (3) the composition of the samples was often not u'ell characterized. This last consideration is especially important, since the carbon sublattice of these materials can accommodate nearly 50\% vacancies and retain the rock-sali cubic structure. Such large numbers of vacancies strongly' influence the electrical properies and make accurate knowledge of the composition essential.

We previously published a systematic study of the iemperature dependence of the electrical resistivities of four single-crystalline transition-metal carbides. ${ }^{1}$ The study revealed resistivities that are well described by either the Block-Gruneisen or the Wilson equations for electron transpon in metals, depending upon whether or not the crystals exhibit superconductivity' above liquid helium temperature. The study is extended in this article 10 include five additional crstals. Also, the resistivity measurements are extended from 350 temperalure $101000 \mathrm{~K}$. These data allow an interpretation of resistivity saturation at high temperatures for the transition-metal carbides. In addition, Hall coefficients are reported for temperatures between 4 and $350 \mathrm{~K}$. The measurements provide infomation about the change of carrier density with composition and indicate that the low-temperature Hall mobility is inversely proportional to the carbon vacancy concentration, independent of the metal constituent. Hence, electrical properties data per se verify the carbon content of the crystals and thereby insure the quality' of the results in this imporant aspect. Moreover, the measurements enable, critical comparisons with other experimental results, with results of band-structure calculations, and with uansport theory. 


\section{EXPERIMENTAL ASPECTS}

Transition-metal carbide single cty'stals were grow'n by the rf noating-zone method, with the exception of an HfC crystal which was prepared by a strain-anneal method. Crystals of TiC 0.95 . $\mathrm{Z} \mathrm{CC}_{0.98}$, and $\mathrm{Z} \mathrm{CC}_{0.93}$ were grow'n at Oak Ridge National Laboratory (ORNL) and chemically analyzed by Teledyne Wah Chang of Albany, Oregon, to establish carbon content. Crystals of $\mathrm{TiC}_{0.92}$ and $\mathrm{Z} \mathrm{C}_{0.89}$ were grown at Martin Marietra Laboratories by Walter Precht, who provided the crystals and their compositions. The crystal of $\mathrm{HfC} 0.99$. grown by Westinghouse Astronuclear Laboratory, was oblained from H. G. Smith of ORNL, who purchased it from Alpha Crystals. This crystal exhibited a grain boundary and a small pore and was of poorer quality than the other samples. All cry'stals w'ere cut into platelets with a thickness of avout 0.5 $\mathrm{mm}$ and lateral dimensions of several millimeters.

Electrical resistivities and Hall coefficients were measured by the method of van der Paun.12 using currents of 0.3 to 1.0 A. Voltages were measured with a Keithley 181 nanovoltmeler. An $8 \mathrm{kG}$ Varian electromagnet was used for Hall measurements. The measurement sequence was automated using a Hewlell-Packard 3495A scanner controlled by a Hew'lell-Packard 9825 computer, which also performed stability checks on the measurements, controlled the temperature, acquired the data, and analyzed the results. Measurements between 4 and $350 \mathrm{~K}$ employed an Air Products LT-3-110 liquid-transfer refrigeration system. Rhodjum-plated, spring-loaded contacts (Augat Pylon Co.) made electrical connection to the sample, which w'as insulated from a copper cold finger by a thin sapphire plate. Temperature was controlled and measured using a Scientific Instruments 5500-APD-K controller and $\mathrm{GaAs}$ themometers mounted on the cold finger. Al temperatures between 300 and $1000 \mathrm{~K}$, a Lindberg clam shell furnace with a Eurotherm $818 \mathrm{~S}$ digital controller was used. A crjstal was held by a jig made of macor and alunina in an evacuated quarz tube. Platinum electrical contacts to the sample were spring-loaded from outside the hot zone of the furnace. Temperature was sensed by a $\mathrm{NiCr} / \mathrm{NiAl}$ type $\mathrm{K}$ thermocouple. 
High-and low-temperature measurements were combined by adjusting one of the data sets with a muluplicative factor to oblain agreement in their region of overlap between 300 and $350 \mathrm{~K}$. This adjustment was usually no more than one percent, and it can be attributed to minor differences in the contact placement. The absolute accuracy of the resistivity measurements is limited by uncertainty in sample and contact geometry and is estimated at 3\%. Precision and relative accuracy are much beller. Typical measurements exhibited a standard deviation of about $50 \mathrm{n} \Omega \mathrm{cm}$. However, the accuracy of temperature control is estimated at $1 \mathrm{~K}$, which contributes an additional $50 \mathrm{n} \Omega \mathrm{cm}$ of uncerainty to a typical resistivity measurement. Although temperature control is poorer near liquid helium temperature, a much lower temperature coefficient of the resistivity tends to compensate. The total uncerainty contributed by the measurements conbined with the temperature uncertainty is estimas to be $70 \mathrm{n} \Omega \mathrm{cm}$.

The absolute accuracy of the Hall measurements is also estimated at 37 because it results from the same geometrical factors. The standard deviation of the Hall measurements is iypically about $2 \times 10^{-11} \mathrm{~m}^{3} / \mathrm{C}$, and the $1 \mathrm{~K}$ temperature uncenainty contribures about $1 \times 10^{-11} \mathrm{~m}^{3} / \mathrm{C}$, so the total statistical error is about $2.2 \times 10^{-11} \mathrm{~m}^{3} / \mathrm{C}$. However, five separate measurements were usually averaged to obtain a final error estimated at $1 \times 10^{-11} \mathrm{~m}^{3} / \mathrm{C}$.

\section{RESULTS}

Resistivities and Hall coefficients measured at temperatures between 4 and $350 \mathrm{~K}$ are show'n in Figs. 1 and 2 for the nearly stoichiometric cr'stals $\mathrm{ZrC}_{0.98}$ and $\mathrm{HfC}_{0.99}$. The least-squares method was used to fit theoretical expressions (shown as solid curves) to the resistivities. The best fit to the $\mathrm{Zr}_{r} \mathrm{C}_{0.98}$ resistivity was obtained with the Bloch-Gruneisen expression:

$$
\rho(T)=\rho_{0}+4 \rho_{1} T(T / \theta)^{4}{ }_{5}(\theta / T) .
$$

The constant $\rho_{0}$ is the residual resistivity at low temperature, and $\rho_{1}$ is the derivative of the resistivity with respect to temperature in the high-temperature linit. The parameter $\theta$ is a 
characteristic temperature which is equal to the Debye temperature in the Bloch-Gruneisen theory. The function $J_{s}(\theta / T)$ is the transport integral defined by

$$
J_{n}(\theta / T)=2^{n-1} \int_{0}^{\theta / 2 T} x^{n} / \sinh ^{2} x d x
$$

where $\mathrm{T}$ is the absolute temperature. The best fit to the resistivity of the HfC 0.99 crystal is obtained with the Wilson expression:

$$
\rho(T)=\rho_{0}+2 \rho_{1} T(T / \theta)^{2} J_{3}(\theta / T)
$$

As in Eq. (1), the expression is nomalized so that $p_{1}$ is the slope of the resistivity curie at high temperature.

Table I gives parameter values that provide the best fits of Eqs. (1) or (3) to resistivity measurements at temperatures up $10350 \mathrm{~K}$ for all the crystals studied. The uncerainty of the parameter values and the standard deriation of the data about the curve were calculated by the method described by Bevington. ${ }^{13}$ The Bloch-Gruneisen equation gives the best fit to all resistivities except for the $\mathrm{HfC}_{0.99}$ crjstal. However, a relatively poor fit to the $\mathrm{HFC}_{0.99}$ resistivity is obtained with tither equation, and based upon our estimate of $70 \mathrm{n} \Omega \mathrm{cm}$ for the variance of the resistivity measurements, neither fit of $\mathrm{HCC}_{0.99} \mathrm{H} \cdot \mathrm{ill}$ pass the chi square test.

Several trends are apparent in Table I. The increase in residual resistivity $\rho_{0}$ with decreasing carbon content is logically attributed to electron scaltering from carbon vacancies. The increase in $\rho_{1}$ with carbon content suggests that the carrier concentration decreases or that Matthiessen's rule is violated. ${ }^{3}$ Hall data and band structure calculations suggest that it is the carrier concentration that decreases. The $\theta$ values are in good agreement with Debye temperatures found from elastic constant measurements, specific heat measurements, and $\mathrm{X}$ ray scaltering. 2.14 The Debye temperatures vary from about $400-900 \mathrm{~K}$, with elastic constants giving the highest values and $x$-ray scattering giving the lowest values. In Table 1 , $\theta$ varies from $539-703 \mathrm{~K}$. 
constants giving the highest values and $x$-ray scattering giving the lowest values. In Table $I$. $\theta$ varies from $539-703 \mathrm{~K}$.

The resistivity data show'n in Figs. 1 and 2 can be compared to similar measurements by Clinard and Kempter ${ }^{7}$ on hot-pressed, polycrystalline samples with a carbon content nearly identical to that of our single crystals. It is surprising that the residual resistivities of the polycrystalline samples are much lower than those of the single crystals. A polycrystalline sample of $\mathrm{Z} \mathrm{C}_{0.98}$ exhibited a $\rho_{0}$ of $26 \mu \Omega \mathrm{cm}$, which is in striking contrast to the po of 139.7 that we measured for a single crystal. Clinard and Kempter found residual resistivities of 17.3 and $13.5 \mu \Omega \mathrm{cm}$ for polycrystalline $\mathrm{HCC}_{0.98}$ and $\mathrm{HFC}_{0.97}$, respectively: which is about a factor of 2 lower than we repor for a single crystal of $\mathrm{HrC}_{0.99}$. The explanation of these discrepancies is not clear, but in contrast to expectations, it is apparent that the poly'crystalline samples have lower residual resistivities than do single crystals. Piper 5,6 found that a single crystal of $\mathrm{TiC}_{0.96}$ has a resistivity much larger than that of the same material after being crushed and hot pressed. Clinard and Kempter ${ }^{7}$ also filted the Bloch-Gruneisen expression to their resistivities, but they only used data for temperatures between 110 and $300 \mathrm{~K}$ for $\mathrm{ZrC}_{0.98}$ and between about 145 and $300 \mathrm{~K}$ for $\mathrm{HFC}_{\mathrm{x}}$. They' found values for $p_{1}$ and $\theta$ that are within about $20 \%$ of the values that we find for single crystals. This is good agreement considering the differences in the temperature ranges of the data that were fitted and the large differences in the values for $p_{0}$.

Figure 3 shows Hall data measured at temperatures between 4 and $350 \mathrm{~K}$ for samples of $\mathrm{TiC}$ and $\mathrm{ZrC}$ that are well off stoichiometry. These data are well described by the empirical formula

$$
R(T)=R_{0}\left[1-\exp \left(-T_{0} / T\right)\right]
$$

where $R_{0}$ represents the low-temperature limit and $T_{0}$ is a characteristic temperature for the data. The solid curves of Fig. 3 represent least-squares fits of this formula to the data, and 
the parameters for the curves are given in Table 11 . Unfortunately, Eq. (4) does not fit the more temperature-dependent data for the nearly stoichiometric crystals as well, and the Hall data of Figs. 1 and 2 have been filted 10 smooth curves that have no simple mathematical expression. The magnitude, the dependence on carbon content, and the temperature variation of the Hall data are in reasonable agreement with measurements made by Williams ${ }^{4}$ and by Piper 5.6 on single crystals of $\mathrm{TiC}_{\mathbf{x}}$. However, most of the Hall data of Table 11 are in poor agreement with measurements that have been made on polycrystalline samples. ${ }^{2}$

A crude interpretation of the Hall data can be made if a single band with a spherical Fermi surface is assumed, and the relaxation time anisotropy is neglected. The Hall constant is then simply related to the carrier density $N$ and the density of states at the Fermi surface $N\left(E_{F}\right):$

$$
R=A / e N=\left(3 m^{3} / \pi^{4} \hbar^{6}\right) /[N(E F)]^{3}
$$

where $A$ is an anisotropy factor, which is assumed equal to unity, although it is probably somewhat larger than unity. V'alues calculated for $N$ and $N\left(E_{F}\right)$ using $R_{0}$ and a free-electron mass have been included in Table 11. The values for $N\left(E_{F}\right)$ are less than half the $0.2-0.6$ that is found from band structure calculations for the materials. ${ }^{15-22}$ Some what better agreement with the calculations is oblained if room temperature Hall data are used in Eq. (5). However, the agreement with band structure calculations is good, considering the approximations made in Eq. (5). The temperature dependence of the data probably originates in the neglected anisotrony factor, although some investigators have atuibuted the temperature dependence to themally' generated carriers. 3,4,9 Band structure calculations also indicate an increase in $N\left(E_{F}\right)$ as the carbon content of the crystals decreases, which is a trend seen in the data of Table 11. In fact, Marksteiner ${ }^{15}$ prejicts a $54 \%$ increase in $N\left(E_{F}\right)$ for $\mathrm{Zr}_{\mathrm{X}}$ as $\mathrm{x}$ decreases from 0.98 to 0.89 , which is in good agreement with the $43 \%$ increase seen in Table 11 . Other investigators computed carrier densities that are roughly twice those of Table II, primarily' because they used room-temperature rather than low-temperature Hall data. ${ }^{2}$ 
Plasma frequencies can be compuled from the carrier densities inferred from the Hall measurements.

$$
E_{p}^{2}=\left(\hbar \omega_{p}\right)^{2}=(4 \pi / 3)\left(e^{2} \hbar^{2}\right) N\left(E_{F}\right) V_{F}^{2}=4 \pi N e^{2} / m
$$

where $\omega_{p}$ is the plasma frequency, $E_{p}$ is the corresponding energy and $V_{F}$ is the Fermi velocity. Values for $E_{p}$ of 1.3 to $2.2 \mathrm{eV}$ are obtained from the densities of Table II and have been included in the table. The resuli for $\mathrm{Zr} \mathrm{C}_{0.89}$ allows interesting comparisons. A value of $E_{p}=2.2 \mathrm{eV}$ is obtained from the low'-temperature Hall coefficient, but $3.4 \mathrm{eV}$ is obtained from the room-temperature result. A previous study 23 of the room temperature optical properties of this crjstal yielded a value of $3.3 \mathrm{eV}$ and a similas unpublished study of the $\mathrm{TiC}_{0.92} \mathrm{cr}$ 'stal yielded a value of $3.1 \mathrm{eV}$. Band structure calculations ${ }^{24}$ have yielded a value of $3.1 \mathrm{eV}$ for a stoichiometric $\mathrm{ZrC}$ crj'stal. Room temperature Hall coefficients appear to give a better prediction of the carrier concentrations than do low-temperature coefficients. However, this result is very likely fortuitous. The Hall measurements are more consistent with the optical results and the band structure calculations if the anisotropy factor $A$ is approximately 2 at low temperalure and nearly unity at room temperature. The temperature dependence of A presumably' results from the increasing importance of phonon scattering at high semperatures.

To the extent that the Hall coefficient measures the carrier density and the low'temperature resistivity is dominated by carbon vacancy scaltering, the Hall mobility at low temperature should be inversely proporional to the number of carbon vacancies.

$$
\mu_{0}=R_{0} / \rho_{0}=\mathrm{eA} / \mathrm{mV} V_{F} \sigma \mathrm{N} v
$$

where $\sigma_{V}$ and $N_{V}$ are the scatrering cross section and the density, respectively, of carbon vacancies. Figure 4 is a plot of the inverse Hall mobility versus the vacancy concentration deduced from chemical analy'sis for all the cry'stals studied. The plot verifies Eq. (7), and it suggests that (1) the low-temperature llall coefficient is inversely proportional to carrier 
density, (2) the low-temperature Hall mobility is independent of the metal constituent for the group IV-B transition-metal carbides, and (3) the carbon content of the crystals has been accurately determined. However, whereas a good fit to Eq. (7) implies that AVV VF is material independent at low' temperature, the Hall coefficient is inversely proporional to the carrier density only if $A$ is individually material independent [see Eq. (5)]. A data point taken from results of Williams ${ }^{4}$ has been included in Fig. 4 to show consistency with an independent study by another researcher.

At high temperatures, the resistivities of transition-metal carbides deviate from the linear dependence on temperature predicted by the Bloch-Gruneisen and W'ilson theories and tend to saturate at a constant value. Figures 5 and 6 show resistivity measurements at temperatures between 4 and $1000 \mathrm{~K}$ for crystals of $\mathrm{TiC}_{\mathrm{x}}$ and $\mathrm{ZrC}_{\mathrm{x}}$. The data were fil with a parallel resistance model in which the temperature-dependent resistivity is in parallel with a constant resistivity po. 25

$$
\rho_{101}=\rho(T) /\left[1+\rho(T) / \rho_{\infty}\right]
$$

where the temperature dependent contribution $\rho(T)$ can have either the Bloch-Gruneisen or the Wilson form [i.e., Eq. (1) or (3)]. Table IIl show's the parameters obtained by fitting Eq. (8) to the resistivities of the samples. The quality of the fits is similar to that described in Table 1. The fits are excellent, but the fit to the HfC 0.99 data fails a chi-square test for either the Bloch-Gruneisen or the Wilson temperature dependence.

In comparison to the values in Table $\mathrm{J}$, the values of $\rho_{0}$ in Table IIl are increased by more than 50\%, except for $H \mathrm{CC}_{0.99}$. Hence, saturation effects are substantial even at the lowest temperatures for cry'stals with high residual resistivities. Moreover, the values for $p_{1}$, which is a measure of the strength of the electron-phonon interaction, are increased by as much as a factor of 3 over the values in Table 1 . This implies that $\rho_{1}$ can be accurately determined only from measurements at temperatures that are high enough to allow $\rho_{\infty}$ to be 
evaluated. A most surprising result is that the $p_{\infty}$ values are more variable than the $p_{0}$ values and that $p_{\infty}$ increases with the carrier density and defect concentration.

An increase in $p_{\infty}$ with $N$ is unexpected because the saturation resistivity is thought to be associated with a decrease in a mean-free path toward a minimum value equal to the interatomic spacing 26,27

$$
\rho_{\infty}=m V_{F} / e^{2} a N=\left(\hbar / e^{2}\right)\left(3 \pi^{2} / a^{3} N^{2}\right)^{1 / 3}=1.27 \times 10^{10} / a^{2 / 3}
$$

where $a$ is the interatomic spacing and $V_{F}$ is related to $\mathrm{N}$ using the spherical Fermi surface approximation. The right-hand expression yiclds $p_{\infty}$ in $\mu \Omega \mathrm{cm}$ when a and $N$ are measured in $\mathrm{cm}$. Although the accuracy of the approximations is questionable, the predicted inverse relationship between $\rho_{\infty}$ and $\mathrm{N}$ should be correct; but it is not observed in the results. Nevertheless, if the lattice constant is used for a and the optically determined plasma frequency of $3.3 \mathrm{eV}$ is used to calculate $\mathrm{N}$ for $\mathrm{ZrC} \mathrm{C}_{0.89}$ from $\mathrm{Eq}$. (6), a value for $\mathrm{p}_{\infty}$ of $681 \mu \Omega \mathrm{cm}$ is found from Eq. (9). This is in rough agreement with the value of $574 \mu \Omega \mathrm{cm}$ found from high-temperature resistivity measurements.

The temperature dependent $\rho(T)$ is contributed by electron scattering from phonons which give a scattering cross section that is directy proportional to the temperature at ele vated temperature. The phonon contribution to the relaxation time at high temperature is

$$
1 / \tau_{c p}=\omega_{p}^{2} \rho_{1} T / 4 \pi=2 \pi \lambda_{L r} k_{B} T / \hbar
$$

where $\lambda_{U}$ is the electron-phonon coupling parameter appropriate to electuon transpon, but which is approximately the mass enhancement $\lambda$ that detennines the superconducting uransition temperalure. ${ }^{28,29}$

$$
\lambda_{L}=\rho_{I} E_{p}^{2} / 8 \pi^{2} \hbar k_{B}=0.248 \rho_{1} E_{p}^{2} \text {. }
$$

where the right-hand expression holds for $\rho_{1}^{\prime}$ in units of $\mu \Omega \mathrm{cm} / \mathrm{K}$ and $E_{p}$ in $\mathrm{eV}$. 
The values of $\lambda_{\text {tr }}$ can be calculated from Eq. (11) by using the parameters in Tables II and III. However, it is probably better to use optically determined values for $E_{\mathrm{p}}$ or to increase the $E_{\mathrm{p}}$ values in Table II by $\sqrt{ } 2$ to account for the anisotropy factor estimated as $A=2$ at low temperatures. Using the optical values of 3.1 and $3.3 \mathrm{eV}$ for the phonon energies of $\mathrm{TiC}_{0.92}$ and $\mathrm{ZrC}_{0.98}$ gives 0.23 and 0.28 for $\lambda_{\text {tr }}$ respectively. The $\mathrm{ZrC}_{0.98}$ crystal exhibits the highest value of $\rho_{1}$ in Table III, but the plasma energy is only $1.87 \mathrm{eV}$, even when adjusted for anisotropy, and $\lambda_{\mathrm{tr}}=0.20$ is found from Eq. (11). The more nearly stoichiometric crystals exhibit higher temperature coefficients, but have lower carrier densities. Hence, it is likely that the electron-phonon-coupling parameter can exceed about 0.3 for the group-IV $B$ transition metal carbides. Superconducting transition temperatures can be estimated by using the values found for $\theta$ and $\lambda_{\mathrm{tr}}$ for $\theta_{\mathrm{D}}$ and $\lambda$, respectively, in the McMillan equation: ${ }^{30}$

$$
T_{c}=\frac{\theta_{D}}{1.45} \exp \left\{\frac{-1.04(1+\lambda)}{\lambda-\mu^{*}(1+0.62 \lambda)}\right\}
$$

where $\mu^{*}$ is the Coulomb coupling constant which is usually estimated to be $0.10-0.13$. The calculated transition temperatures are much less than $0.1 \mathrm{~K}$, which is consisterit with the absence of observed superconductivity in the group-IV $B$ carbides.

Gurvitch recently proposed a universal phase diagram that associates $\lambda$ and $\rho_{0}$ with $n$, the power-law exponent in the temperature dependence of the resistivity at low temperature. ${ }^{31}$ In his theory, the simultaneous presence of strong electron-phonon coupling (measured by $\lambda$ ) and disorder (measured by $\rho_{0}$ ) produces a transition from a classical region of $n=3-5$ to a region od $n=2$ at a phase boundary defined by

$$
(\lambda-0.7) \rho_{o}=13 \mu \Omega \mathrm{cm} .
$$

The parameter of this equation for the group IVB transition-metal carbides are consistent with this classification. At low temperature, the Bloch-Grüneisen and Wilson equations vary as $T^{5}$ 
and $T^{3}$, respectively, and the weak electron-phonon coupling (i.e., $\lambda<0.7$ ) clearly places these maierials in the classical region independent of the is $p_{0}$ values.

\section{CONCLUSIONS}

- The Bloch-Gnuneisen theory gives an excellent description of the temperature dependence of the electrical resistivities of the $\mathrm{TiC}_{x}$ and $\mathrm{Z} \sim \mathrm{C}_{x}$ crystals, but a different temperature dependence is found for $\mathrm{HFC}$.99. The W'ilson model gives a better fil-but not a good fit-to the $\mathrm{HFC}_{0.99}$ data; whereas it gives an excellent fil to the resistivities of the superconducting tansition-metal carbides of group V-B.' Although the quality of the :HfC 0.99 crystal is suspect, it is probably not responsible for the different temperature dependence.

Although the Bloch-Gruneisen and Wilson models provide convenien descriptions of the resistivity data, there is no a priori reason to expect these descripuions to be accurate. Both models are based upon restrictive assumptions. The Bloch-Gruneisen equation is obtained from a lowest order variational approximation to the Boltzmann equation in which a rigid shift of the Fermi surface and a Debye phonon spectrum are assumed, and the Wilson equation assumes electron scattering between $s$ and $d$ bands that is improbable in the transition-metal carbides.

There are significant differences between the resistivities (and also the Hall coefficients) of single crystalline and polycrystalline samples of the same transition-metal carbide. The lower residual resistivities of polycrystalline samples are especially remarkable because single cn'stals should have more nearly perfect order and, therefore, should exhibit less defect and grain-boundary scattering. The origin of these differences in electrical properies is unknown.

The Hall measurements are particularly valuable because they verify the carbon content of the crystals, which is 100 often a deficiency of other studies, and ir so doing suggest that carrier densities can be inferred from the low-temperature Hall coefficients. Clearly, the 
carrier densities are uncertain to within a temperature dependent anisotropy factor that decreases as the relative importance of phonon and defect scaltering changes with temperature. Even larger uncerainties enter into the calculations of plasma frequencies and densities of states, because the Fermi velocity and effective mass should take Fermi surface geomery into accurate account. Nevernheless, the implied change in these parameters with carbon content roughly agrees with band structure calculations.

The transition-metal carbides exhibit a resistivity saturation at elevated temperature, which is well described by the parallel resistance model. However, the results reveal a saturation resistance that increases with the carbon vacancy concentration. This is surprising because both the Hall measurements and band structure calculations suggest that the carrier concentration increases with the carbon vacancy concentration. Hence, the saturation resistance should decrease rather than increase. The reason for the increase is obscure, but it is probably naive to assume that there is no dependence of the minimum mean-free path on the vacancy concentration. In any case, a rough calculation of the saturation resistance is in reasonable agreement with the measurements, and the concept of a minimum mean-free path that is related to the lattice constant seems to be verified for the materials.

Electron lattice coupling parameters can be calculated from the resistivity data and the Hall coefficients, although optical studies give a more reliable estimate of the plasma frequency. Moreover, superconducting transition temperatures can be estimated from the various parameters, all of which are experimentally determined. The predicted transition temperatures are consistent with the lack of superconductivity in the group IV-B transitionmetal carbides. It is interesting that the electron-phonon coupling as measured by temperature derivative of the resistivity, is as large or larger than that of the superconducting group V-B transition-metal carbides.' Hence, the group IV-B materials are not superconducting because their carrier densities and plasma frequencies are low. The carrier density increases substantially as the carbon content of the materials decreases, but this 
increase is offset by a corresponding reduction in the electron-phonon coupling that is revealed by the temperature derivative of the resistivity.

\section{RADIATION DAMAGE STUDIES EXPERIMENTAL CONSIDERATIONS}

The single crystal $V C_{0.88}$ used in this work was a gift of F. A. Modine. This composition corresponds to the cubic ordered phase $\mathrm{V}_{8} \mathrm{C}_{7}$ where the vacancies are arranged on periodically on a complex superlattice. Superlattice spots and domain boundaries were clearly visible in electron micrographs of the unirradiated samples. Both the superlattice spots and the domain boundaries disappeared when the samples were irradiated for several minutes in a $100 \mathrm{keV}$ electron microscope.

Resistivities were measured from 10 to $300 \mathrm{~K}$ by the van der Pauw technique[12] on samples mounted on the coldhead of a closed-cycle helium cryostat. For these measurements samples of $\mathrm{VC}_{0.88}$ were cut into $5 \mathrm{~mm} \times 5 \mathrm{~mm}$ squares using a diamond saw. They were then polished with diamond paste to assure uniform thickness. The results reported here were obtained on samples $0.4318 \mathrm{~mm}$ and $0.5842 \mathrm{~m} . \mathrm{m}$ thick.

In order to maintain accurate and reproducible results, careful attention was given to electrical and thermal contact and accurate placement of the electrical leads. A sample holder was designed that made electrical contact with each corner of the sample by means of a platinum wire held in place by spring-loaded aluminum arms. These arms were set in a ring of machinable ceramic (macor) which was spring loaded to a copper block. The sample was thermally anchored to the copper block, but electrically insulated from it, by a sapphire disc $12 \mathrm{~mm}$ in diameter and $1 \mathrm{~mm}^{\prime}$ thick. Thermal contact was improved by using a thin layer of thermal compound between the block and the disc and between the disc and the sample. The copper block was bolted to the coldhead of the cryostat which had been 
coated with indium to insure intimate contact. With this arrangement resistivities could be measured to an accuracy of 0.03 micro $\mathrm{Ohm} \mathrm{cm}$.

The electrical resistivity measurements were carried out under the control of a HP 86 microcomputer and a Keithley model 706 scanner which was used to switch the current and voltage leads among the contact placements. A HP 6633A dc power suppiy provided a constant $1 \mathrm{~A}$ current through the sample. This was monitored by a HP 3478A digital multimeter. Potential differences across the sample were measured with a Keithley model 181 digital nanovoltmeter. The sample temperature was monitored with a Lakeshore Cryotronics DT-500-DRC calibratcd silicon diode thermometer mounted in a well in the copper block. This arrangement allowed for shielding the thermometer for the electron beam during irradiations and maintaining good contact with the sample. The end points of our temperature range, the ultimate low temperature of the cryostat, $8.6 \mathrm{~K}$ and ambient temperature, were reproducible to within $0.2 \mathrm{~K}$ (twice the least-count of the digital readout) following numerous thermal and irradiation cycles, the latter representing an aggregate of 12 days irradiation time. A Scientific Instruments temperature controller was used to monitor the thermometer and maintain temperature stability during the irradiations and the measurements. Resistivities were recorded at $5 \mathrm{~K}$ intervals from 10 to $120 \mathrm{~K}$ and at $10 \mathrm{~K}$ intervals between 120 and $300 \mathrm{~K}$ both before and after irradiation.

In situ electron irradiations were carried out at a temperature of $25 \mathrm{~K}$ using the Van de Graaff accelerator at Oklahoma State University. A 50 microA beam current of $1 \mathrm{MeV}$ electrons produced an electron flux of $2.8 \mathrm{microA} / \mathrm{cm}^{-2}$ measured by a Faraday cup located at the sample position. The electron beam was admitted to the cryostat through an aluminum window $25 \mathrm{~mm}$ in diameter and $0.25 \mathrm{~mm}$ thick. This allowed for minimal attenuation of the beam. A $24 \mathrm{hr}$ irradiation $\left(2.7 \times 10^{17}\right.$ electrons $/ \mathrm{cm}^{2}$ on the sample) produced a $10 \%$ change in the residual resistivity at $10 \mathrm{~K}$; further irradiation to a total of 
$96 \mathrm{hr}\left(1.08 \times 10^{18} \mathrm{~cm}^{-2}\right)$ produced a $50 \%$ change. The aluminum window was water-cooled during long irradiations to minimize damage to the o-ring that sealed it to the vacuum space of the cryostat. The window was electrically insulated from the cryostat so that the beam current incident on the window could be monitored continuously during irradiations.

\section{RESULTS AND DISCUSSION}

Typical results for the resistivity of $\mathrm{VC}_{0.88}$ before and after $96 \mathrm{hr}$ irradiation are displayed in Fig. 7. Long irradiation times were necessary in order to achieve significant changes in the residual resistivity. At low doses, less than $\sim 36 \mathrm{hr}$ irradiation time, we believe the displaced carbon atoms are redistributed over the vacancies in the $\mathrm{V}_{8} \mathrm{C}_{7}$ superlattice and thus are relatively ineffective in scattering conduction electrons. Note also that at temperatures above $100 \mathrm{~K}$ the resistivity after $96 \mathrm{hr}$ irradiation is somewhat smaller than that of the sample before irradiation. This point will be discussed below.

Fig. 8 displays the residual resistivity change after $75 \mathrm{hr}$ irradiation followed by 15 min isochronal anneals of the sample. One notes that the initial $10 \%$ increase in residual resistivity induced by the radiation damage persists to a temperature of $80 \mathrm{~K}$ at which point the radiation-induced defects begin to move and the resistivity begins to recover. This process is essentially complete at $100 \mathrm{~K}$. At this point the residual resistivity is $3 \%$ less than that of the sample before irradiation. This indicates that the process of irradiation and low temperature annealing has returned the sample to a state of higher order than was initially present. The sharpness of the annealing stage between these two states of residual resistivity indicates that the radiation-induced defects occupy traps of similar depth. This is consistent with our expectation that $1 \mathrm{MeV}$ electrons should be able to displace only carbon atoms and not vanadium. No further changes in residual resistivity occur between 100 and $300 \mathrm{~K}$. 
The effects of the radiation damage on the temperature dependence of the resistivity are shown in Fig. 9 where the difference between the resistivities measured at the same temperature before and afier irradiation are plotted for irradiation times of $24 \mathrm{hr}$ and 96 hr. The longer irradiation will be discussed first. It can easily be seen in the $96 \mathrm{hr}$ irradiation that at temperatures below the $80 \mathrm{~K}$ annealing stage the resistivity is increased by a constant 0.5 micro $\mathrm{Ohm} \mathrm{cm}$. Comparison with Fig. 8 suggests that the change in resistivity in this range is due to the increased residual resistivity and that the phonon contribution to the resistivity remains the same as before irradiation. At temperatures above $80 \mathrm{~K}$ the resistivity decreases reaching its unirradiated value at $100 \mathrm{~K}$. The resistivity continues to decrease until it has fallen $1 \mathrm{micro} O \mathrm{Ohm} \mathrm{cm}$ below its unirradiated value in the vicinity 200 $K$. This change is well outside the experimental uncertainty and shows that following the annealing stage changes occur in the phonon contribution to the resistivity as well as in the residual resistivity.

The 0.1 micro $\mathrm{Ohm} \mathrm{cm}$ change in the residual resistivity afier a $24 \mathrm{hr}$ irradiation lies just above the experimentally detectable limit. Rather than showing a recovery in the resistivity near $80 \mathrm{~K}$, the resistivity increases with temperature reaching a maximum deviation of 1 micro $\mathrm{Ohm} \mathrm{cm}$ from the unirradiated resistivity at $230 \mathrm{~K}$. Only then does the resistivity begin to recover, suggesting that the defects produced by a $24 \mathrm{hr}$ irradiation are held in deeper traps than are the defects that produce the residual resistivity after longer irradiations.

While we cannot provide a definitive explanation of these seemingly contrary changes in the resistivities of the irradiated, samples at this time, the following suggestion is consistent with our data and with the structure of $\mathrm{VC}_{0.88}$. The superlattice spots observed by electron microscopy show that before irradiation our samples have the $\mathrm{V}_{8} \mathrm{C}_{7}$ ordered 
vacancy structure. This is destroyed by short periods of electron bombardment in the microscope. The smallness of the increase in residual resistivity produced by this earlystage damage suggests that the displaced carbon atoms enter the vacancies sites in the superlattice rather than creating new vacancy-interstitial pairs. The sample would retain its basic rocksalt structure, but the vacancies would be located randomly instead of occupying superlattice sites.

Such a structural change has implications for the phonon-induced resistivity, as well as for the residual resistivity produced by the radiation damage. Before irradiation the primitive cell of the crystal is that of the $\mathrm{V}_{8} \mathrm{C}_{7}$ superlattice. After early-stage damage the crystal structure is determined by the fcc VC lattice with $12 \%$ random vacancies. This change in the primitive cell would enlarge the Brillouin zone and, in so doing, drastically modify the Fermi surface. Different wavevector phonons would then be needed to scatter electrons across the Fermi surface. Depending on the relative electron-phonon coupling constants and thermal populations of the most effective phonons for electrical resistance, the resistivity may either decrease, or as we observe, increase due to this structural modification. A detailed calculation of such complex changes is beyond the scope of this paper.

Longer electron bombardments produce significant numbers of vacancy-interstitial pairs, as well as disordering the vacancies on the carbon sublattice, as is shown by the increase in residual resistivity that results. The annealing stage at $80 \mathrm{~K}$ represents the movement of these defects to recreate the $\mathrm{V}_{8} \mathrm{C}_{7}$ superlattice structure. As we have already noted, the sharpness of the annealing stage suggests that all the mobile defects are held in traps of similar depth. The formation of the superlattice at low temperatures may well contain fewer residual imperfections than are present when it forms from the melt. The annealing stage seen above $230 \mathrm{~K}$ in the résistivity due to early-stage damage suggest that carbons on vacancy-sites in the superlattice are more tightly bound than are interstitials in a more heavily damaged specimen. This would account for the recovery of the resistivity to 
lower values after the $80 \mathrm{~K}$ annealing stage than are seen before irradiation.

\section{HUMAN RESOURCE DEVELOPMENT}

Four M. S.-level students have been supported in part by this project. Two were ethnic minorities under-represented in physics, one Hispanic and one Native American. The latter, H. J. John, completed his thesis work on $\mathrm{VC}_{0.88}$ and is now employed by the Naval Weapons Center, China Lake, CA. Another, Ben Zapata, changed projects on the departure of Prof. Allison and has since completed his degree. He is employed in the energy industry by Halliburton Services. One student has temporarily left graduate school for personal reasons and the fourth is still enrolled but experiencing academic difficulty. In addition to these graduate students two physics undergraduates have participated in this project. 
Table 1. Parameters describing the electrical resistivity of group IV-B transition-metal carbides al temperatures between 0 and $350 \mathrm{~K}$. The values were oblained by fitting the data to the Bloch-Gruneisen expression, excepting that the second set of values for HFC was obtained from a fit to the Wilson model. Standard deviations of the parameters and of the data from the filted function are given.

\begin{tabular}{ccccc}
\hline & $\begin{array}{c}\rho_{0} \\
(n \Omega=\mathrm{m})\end{array}$ & $\begin{array}{c}\rho_{1} \\
(\mathrm{n} \Omega \mathrm{cm} / \mathrm{K})\end{array}$ & $\begin{array}{c}\theta \\
(K)\end{array}$ & $\begin{array}{c}\sigma_{\rho} \\
(\mathrm{n} \Omega \mathrm{cm})\end{array}$ \\
\hline $\mathrm{TiC}_{0.95}$ & $145.5 \pm 0.0$ & $44.01 \pm 0.13$ & $718.6 \pm 5.6$ & 55.5 \\
$\mathrm{TiC}_{0.92}$ & $165.5 \pm 0.0$ & $39.11 \pm 0.16$ & $737.2 \pm 5.1$ & 45.4 \\
$\mathrm{ZrC}_{0.98}$ & $139.7 \pm 0.0$ & $67.37 \pm 0.19$ & $538.7 \pm 4.0$ & 83.3 \\
$\mathrm{ZrC}_{0.93}$ & $180.8 \pm 0.0$ & $48.98 \pm 0.15$ & $569.7 \pm 4.6$ & 64.9 \\
$\mathrm{ZrC}_{0.89}$ & $193.8 \pm 0.0$ & $42.45 \pm 0.13$ & $574.1 \pm 4.1$ & 72.2 \\
$\mathrm{H}_{\mathrm{r}} \mathrm{C}_{0.99}$ & $32.39 \pm 0.8$ & $88.13 \pm 0.86$ & $574.1 \pm 12.9$ & 281.8 \\
$\mathrm{H}_{\mathrm{r}} \mathrm{C}_{0.99}$ & $32.22 \pm 0.5$ & $90.58 \pm 0.57$ & $703.1 \pm 9.7$ & 172.9 \\
\hline
\end{tabular}


Table Il. Parameters describing the Hall coefficients of groug IV-B transition-metal carbides. The low-temperature limit $R_{0}$ and the lemperalure $T_{0}$ are obtained from a fit of $R=$ $R_{0}\left[1-\exp \left(-T_{\delta} T\right)\right]$ to the data. The electron density $N$ and the density of states at the Fermi energy are obtained from $R_{0}$ by assuming a single carrier with an effective mass equal :o the electron mass and a spherical Fermi surface. The $E_{p}$ is a Drudemodel plasma energy calculated from $\mathrm{N}$.

\begin{tabular}{|c|c|c|c|c|c|}
\hline & $\begin{array}{c}R_{\mathrm{o}} \\
\left(\mathrm{mm}^{3} \cdot \mathrm{C}\right)\end{array}$ & $\begin{array}{l}T_{0} \\
(K)\end{array}$ & $\begin{array}{c}100 \times N \\
(1 / \text { cell })\end{array}$ & $\begin{array}{c}N\left(E_{F}\right) \\
(1 / e V \text { cell })\end{array}$ & $\underset{(e V)}{E_{p}}$ \\
\hline $\mathrm{TiC}_{0.95}$ & -2.61 & 255 & 4.84 & 0.112 & 1.82 \\
\hline TiCu.92 & -1.67 & 262 & 7.58 & 0.129 & 2.27 \\
\hline $\mathrm{ZrC} \mathrm{C}_{0.98}$ & -4.96 & $\ldots$ & 3.27 & 0.115 & 1.32 \\
\hline $\mathrm{ZrC}_{0.93}$ & -2.27 & 312 & 7.13 & 0.150 & 1.95 \\
\hline $\mathrm{ZrC}_{0.89}$ & -1.70 & 307 & 9.14 & 0.165 & 2.24 \\
\hline HIC0.99 & -2.66 & $\cdots$ & 5.69 & 0.137 & 1.80 \\
\hline
\end{tabular}


Table III. Parameters describing the electrical resistivity of group IV-B transition-metal carbides at temperatures between 0 and $1000 \mathrm{~K}$. The values were obtained by filting the data to a parallel resistor model in which the temperafure dependent resistivity is given by the Bloch-Gruneisen expression, excepting that the Wilson model of the temperature dependence was used for the second set of values for HCC. Standard deviations of the paramelers and of the data from the filled function are given.

\begin{tabular}{lccccc}
\hline & $\begin{array}{c}\rho_{0} \\
(\mu \Omega \mathrm{cm})\end{array}$ & $\begin{array}{c}\rho_{1} \\
(\mathrm{n} \Omega \mathrm{cm} \sqrt{ })\end{array}$ & $\begin{array}{c}\theta \\
(K)\end{array}$ & $\begin{array}{c}\rho_{\infty} \\
(\mu \Omega \mathrm{cm})\end{array}$ & $\begin{array}{c}\sigma_{\rho} \\
(\mathrm{n} \Omega \mathrm{cm})\end{array}$ \\
\hline $\mathrm{TiC}_{0.95}$ & $233.0 \pm 1.4$ & $120.4 \pm 1.7$ & $749.9 \pm 3.8$ & $388.0 \pm 3.8$ & 54.8 \\
$\mathrm{TiC}_{0.92}$ & $255.4 \pm 1.8$ & $97.23 \pm 1.6$ & $754.6 \pm 3.3$ & $470.1 \pm 6.1$ & 43.1 \\
$\mathrm{ZrC} 0.98$ & $238.9 \pm 0.6$ & $226.3 \pm 1.6$ & $720.1 \pm 3.3$ & $343.5 \pm 1.7$ & 62.7 \\
$\mathrm{ZrC} 0.93$ & $284.9 \pm 3.6$ & $129.1 \pm 3.8$ & $599.8 \pm 5.7$ & $495.1 \pm 10.9$ & 89.8 \\
$\mathrm{ZrC} C_{0.89}$ & $296.7 \pm 3.2$ & $105.3 \pm 2.6$ & $609.9 \pm 4.6$ & $559.0 \pm 11.4$ & 81.9 \\
$\mathrm{H} \mathrm{CC}_{0.99}$ & $34.11 \pm 0.10$ & $104.5 \pm 1.0$ & $619.4 \pm 7.7$ & $675.3 \pm 26.2$ & 236.2 \\
$\mathrm{H} \mathrm{HC}_{0.99}$ & $34.06 \pm 0.07$ & $107.7 \pm 0.7$ & $742.8 \pm 6.3$ & $608.2 \pm 13.8$ & 148.6 \\
\hline
\end{tabular}




\section{REFERENCES}

1. C. Y. Allison, C. B. Finch, M. D. Foegelle, and F. A. Modine, Solid State Commun. 68, 387 (1988).

2. L. E. Toth, Transition Melal Carbides and Nitrides, Academic Press, New York (1971).

3. W. S. Williams, Progress in Solid Siate Chemistry, Vol. 6, ed. by H. Reiss and J. O. McCaldin, Pergamon Press, New York (1971).

4. W. S. Williams, Phj's. Rev. A 135, 505 (1964).

5. J. Piper, J. Appl. Phys. 33, 2394 (1962).

6. J. Piper, Compounds of Interest in A'uclear Reacior Technolog); ed. by' P. Chiolli and W'. $\mathrm{N}$. Miner, Inst. Metals Div. Spec. Rep. No. 3, Edwards, Ann Arbon, Michigan (1964).

7. F. W. Clinard and C. P. Kempler, J. Less-Common Met. 15, 59 (1968).

8. V.S. Neshpor, S. V. Airaperyants, S. S. Ordan'yan, and A. I. Avgustinik, Inorg. Mater. 2. 728 (1966).

9. O. A. Golikova, A. I. Avgustnik, G. M. Klimashin, and L. V. Kozlovskii, Sov. Phys.-Solid State 7, 2317 (1966).

10. O. A. Golikova, F. L. Feigel'man, A. 1. Avgustnik, and G. M. Klimashin, Sov. Phys.Semicond. 1, 236 (1967).

11. I. Vishnevetskaya, A. Gaisanyak, T. Zapadaeva, and V. Petrov, High Temp. High Pressures 13, 665 (1981).

12. L. J. van der Pauw, Philips Res. Reprs. 13, 1 (1958).

13. P. R. Bevington, Data Reduction and Error Analysis for the Physical Sciences, McGraw.Hill, New York (1969).

14. H. Bernstein, Compounds of Interest in Nuclear Reactor Technolog;, ed. by P. Chiolti and W. N. Miner, Inst. Metals Div. Spec. Rep. No. 3, Edwards, Ann Arbon, Michigan (1964).

15. P. Marksteiner, P. Weinberger, A. Neckel, R. Zeller, and P. Dedericks, Phjs. Rev. B 33, 6709 (1986). 


\section{References (coni'd)}

16. P. Marksteiner, P. Weinberger, A. Neckel, R. Zeller, and P. Dedericks, Phys. Rev. B 33, 812 (1986).

17. B. M. Klein, D. A. Papaconstantopoulos, and L. L. Boyer, Phy's. Rev. B 22, 1946 (1980).

18. J. Klima, J. Phys. C 12, 3691 (1979).

19. A. Neckel, P. Rasil, R. Ejbler, P. Weinberger, and K. Schwartz, J. Phjs. C 9, 579 (1976).

20. H. Thara, M. Hirabayashi, and H. Nakagawa, Phjs. Rev. B 14, 1707 (1976).

21. J. F. Alward, C. Y. Fong, M. El-Batanouny, and F. Wooten, Phys. Rev. B 12, 1105 (1975).

22. V. I. Potoracha, V. A. Tskhai, and P. V. Geld, Phys. Stams Solidi b 48, 119 (1971).

23. F. A. Modine, T. Hay'uood, and C. Y'. Allison, Phy's. Rev. B 32, 7743 (1985).

24. D. A. Papaconstantopoulos, private communication (1988).

25. H. Wiesman, M. Gurvitch, H. Lutz, A. Ghosh, B. Schwartz, M. Strongin, P. B. Allen, and J. W. Halley, Phy's. Rev. Lelt. 38, 782 (1977).

26. Z. Fisk and G. W. Webb, Phys. Rev. Letl. 36, 1084 (1976).

27. J. H. Mooij, Phjs. Stallus Solidi a 17, 521 (1973).

28. P. B. Allen, Phys. Rev. B 36, 2920 (1987).

29. P. B. Allen, T. P. Beaulac, F. S. Khan, W. H. Butler, F. J. Pinski, and J. C. Swihan, Phys. Rev. B 34, 4331 (1986).

30. W. L. McMillan, Phy's. Rev. 167, 331 (1968).

31. M. Gurvitch, Phys. Rev. Lett. 56, 647 (1986). 


\section{FIGURE CAPTIONS}

Fig. 1 The resistivity and Hall coefficient of $\mathrm{ZrC}_{0.98}$ measured between 4 and $350 \mathrm{~K}$. Bloch-Grueneisen theory has been fit to the resistivity data.

Fig. 2 The resistivity and Hall coefficient of $\mathrm{HfC}_{0.99}$ measured between 4 and $350 \mathrm{~K}$. Wilson theory has been fit to the data.

Fig. 3 Hall Coefficients of $\mathrm{TiC}_{\mathbf{x}}$ and $\mathrm{ZrC}_{\mathbf{x}}$ measured between 4 and $350 \mathrm{~K}$.

Fig. 4 Low-temperature inverse Hall mobilities of group IV transition metal carbides shown as a function of vacancy concentration. The result for $\mathrm{TiC}_{0.97}$ is from Data of Williams.

Fig. 5 The electrical resistivities of $\mathrm{TiC}_{0.95}$ and $\mathrm{TiC}_{0.92}$ measured between 4 and $1000 \mathrm{~K}$.

Fig. 6 The electrical resistivities of $\mathrm{ZrC}_{0.93}$ and $\mathrm{ZrC}_{0.89}$ measured between 4 and $1000 \mathrm{~K}$.

Fig. 7 Temperature depandence of the electrical resistivity of $\mathrm{VC}_{0.88}$ before and after $96 \mathrm{hr}$ irradiation with $1 \mathrm{MeV}$ electrons at $25 \mathrm{~K}$.

Fig. 8 Behavior of the residual resistivity of $\mathrm{VC}_{0.88}$ following $15 \mathrm{~min}$ isochronal anneals. The residual resistivities were measured at $10 \mathrm{~K}$ following a $75 \mathrm{hr}$ irradiation at $25 \mathrm{~K}$.

Fig. 9 Change in resistivity of $\mathrm{VC}_{0.88}$ as a function of temperature following irradiations of 24 and 96 hrs. 


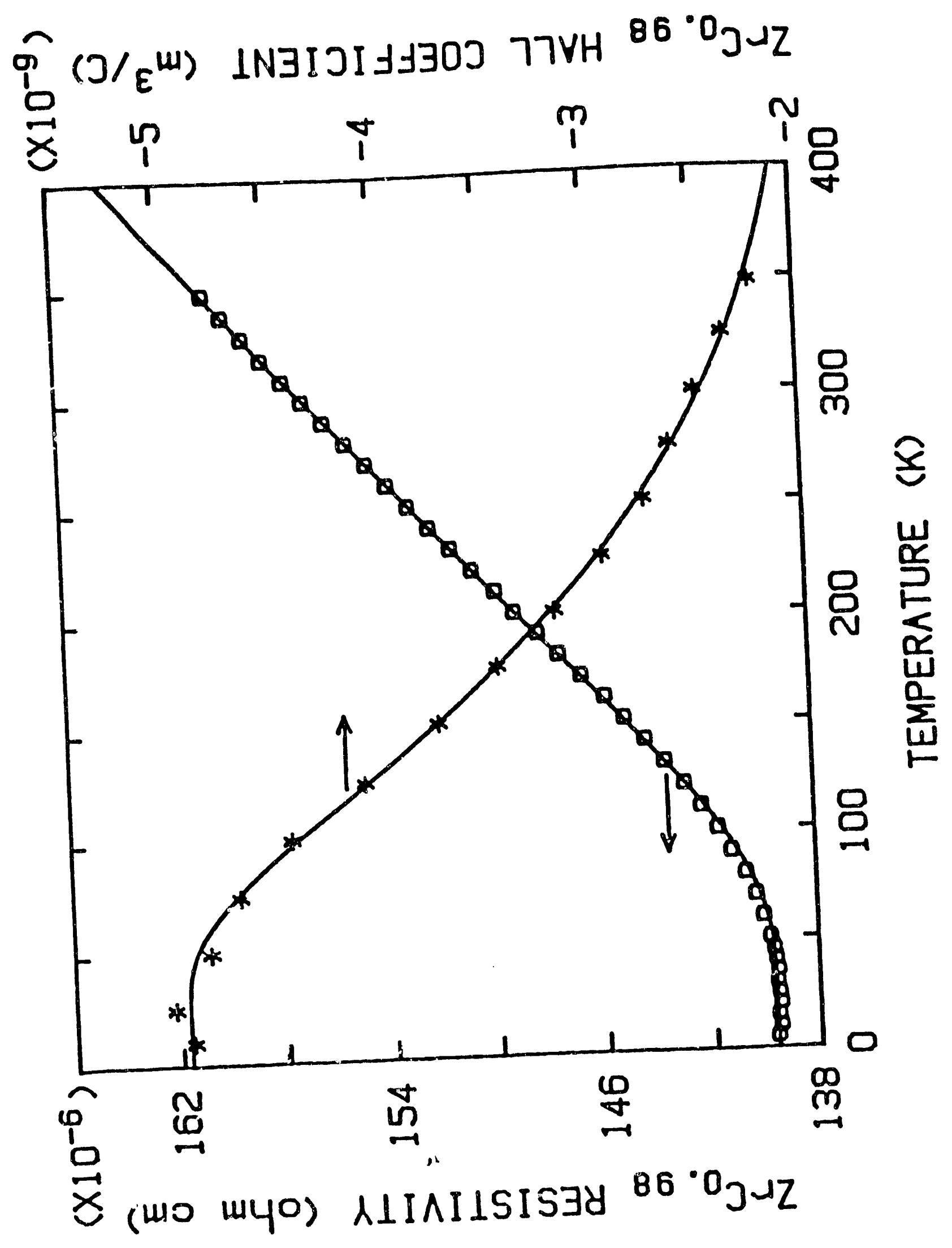

Fig. i 


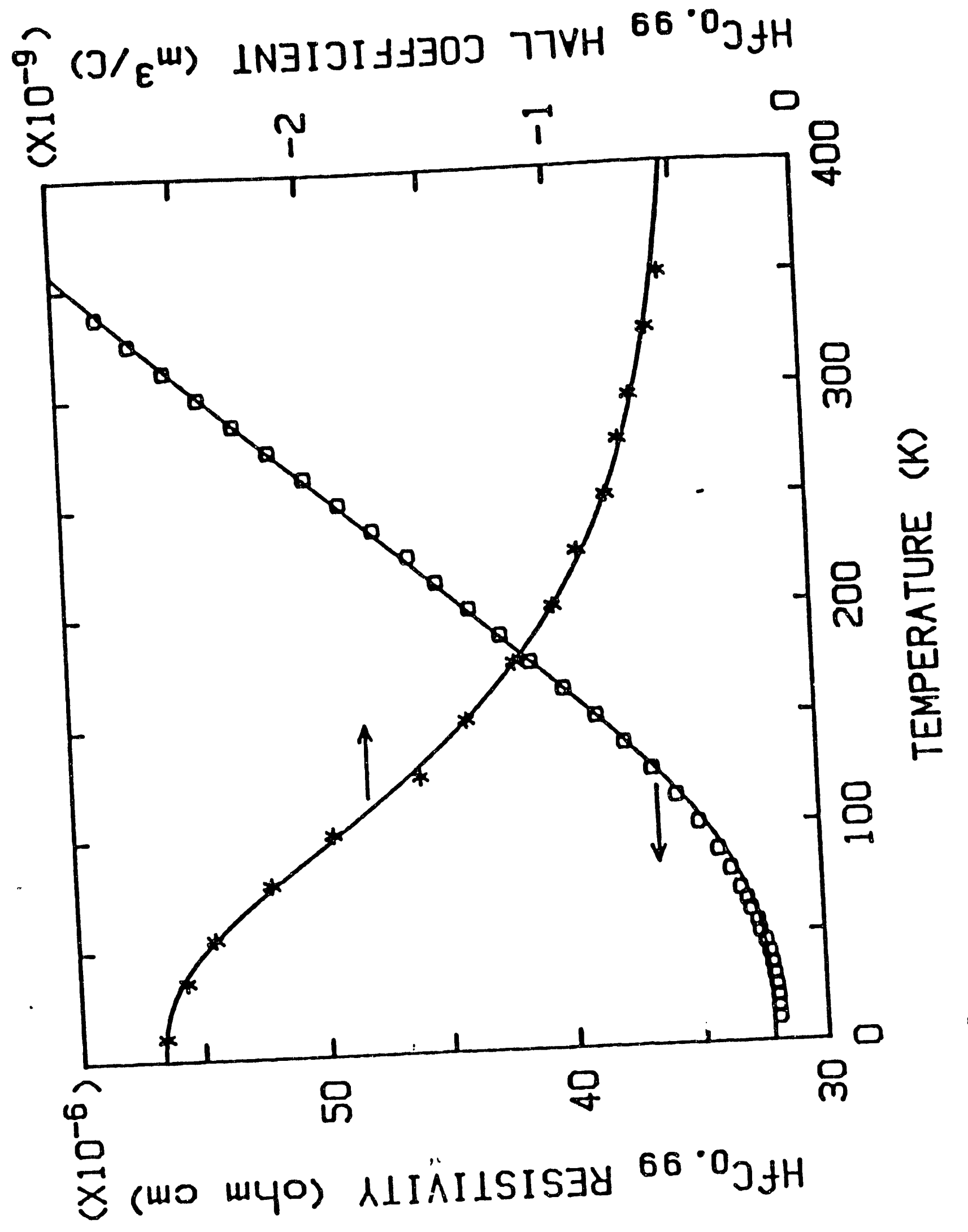

Fig. 2 


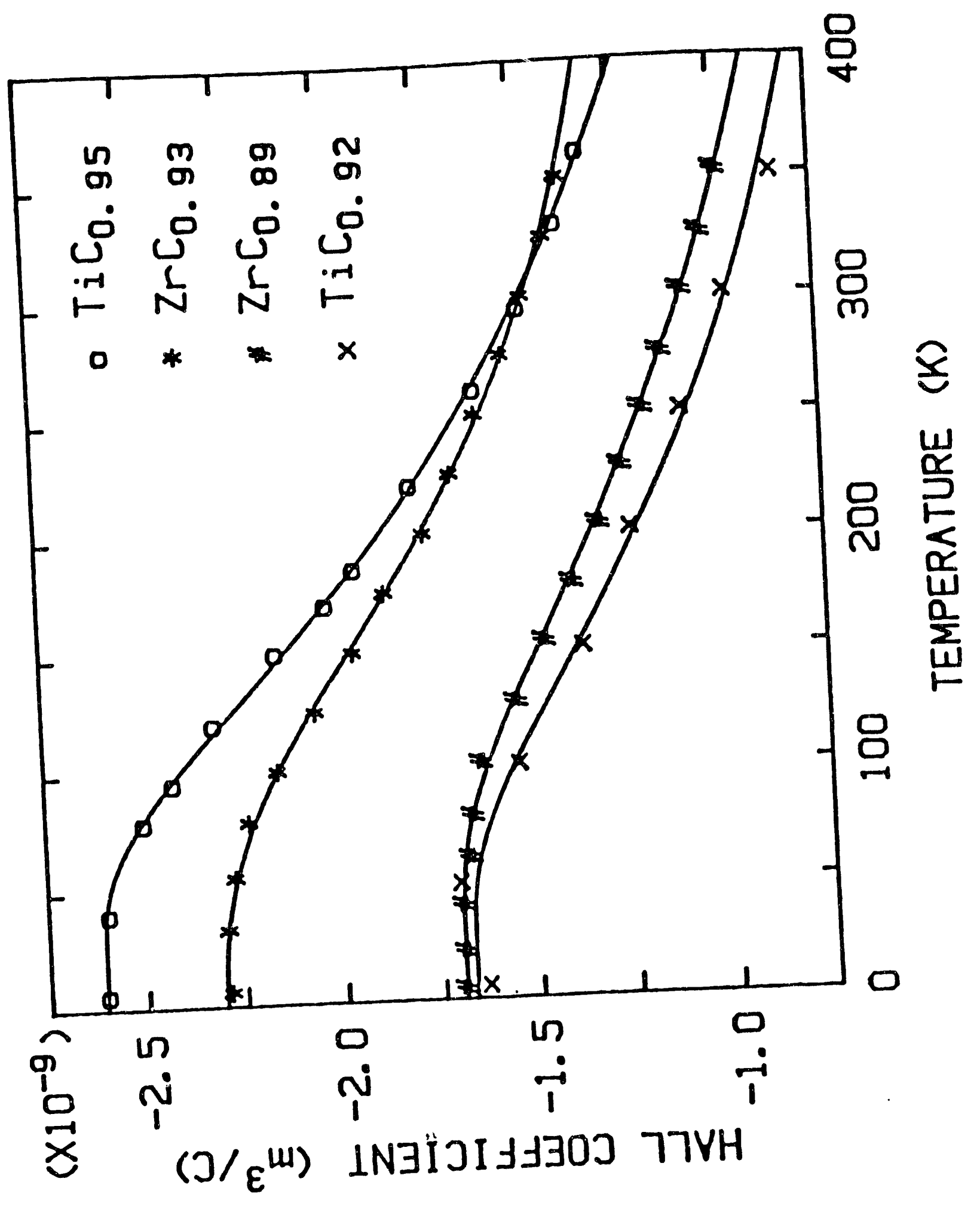

Fig. 3 


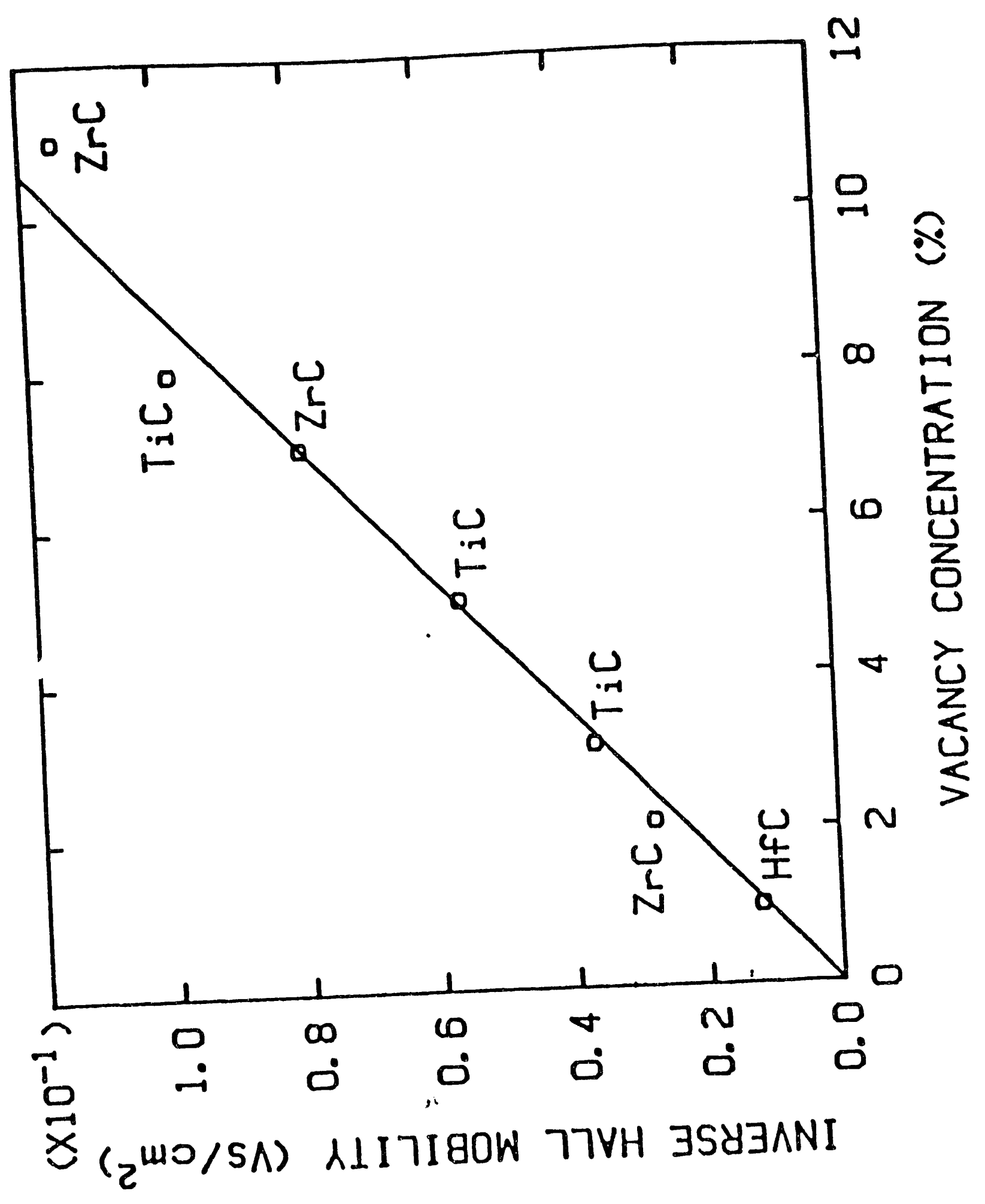

Fig. 4 


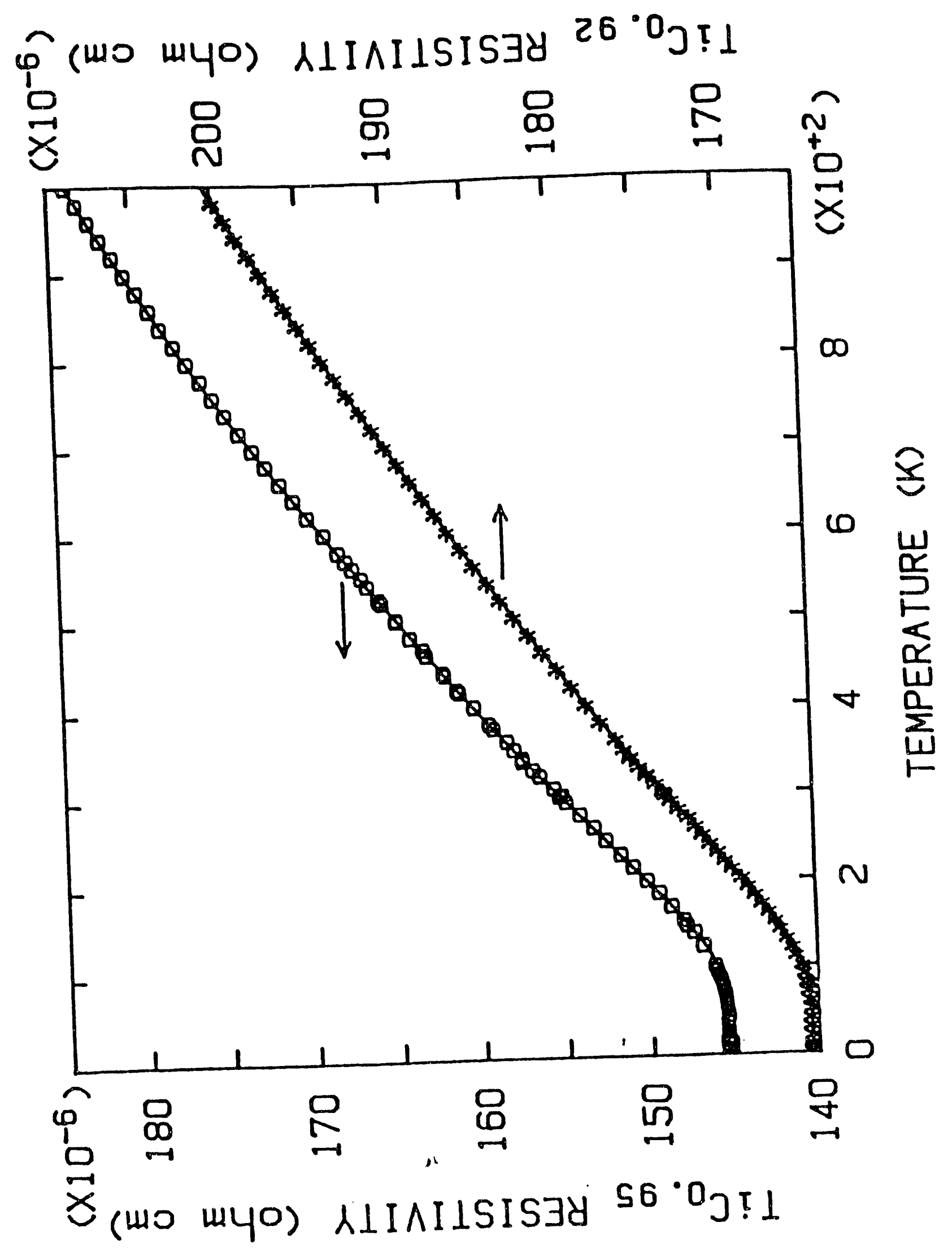

Fig. 5 


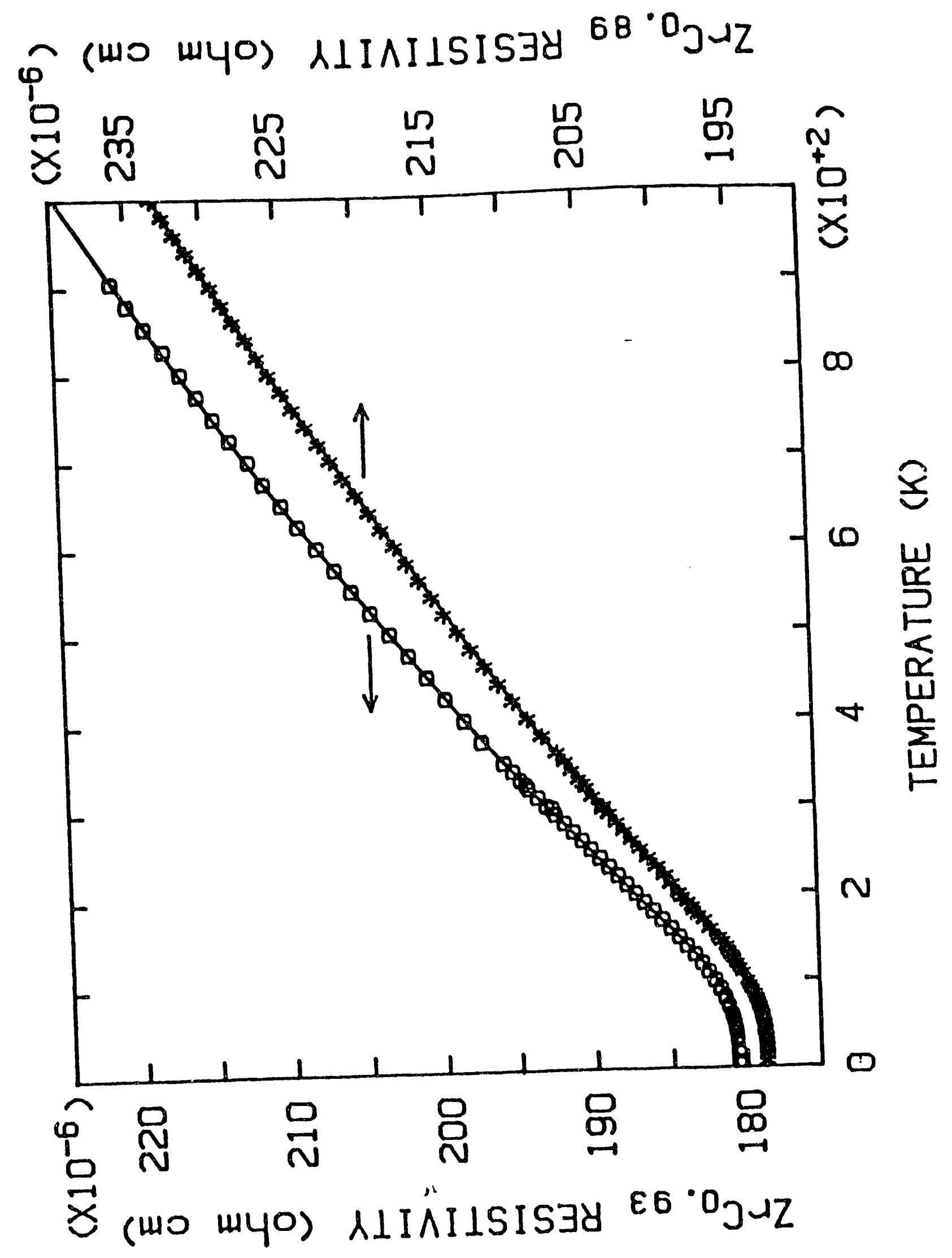

fig. 6 


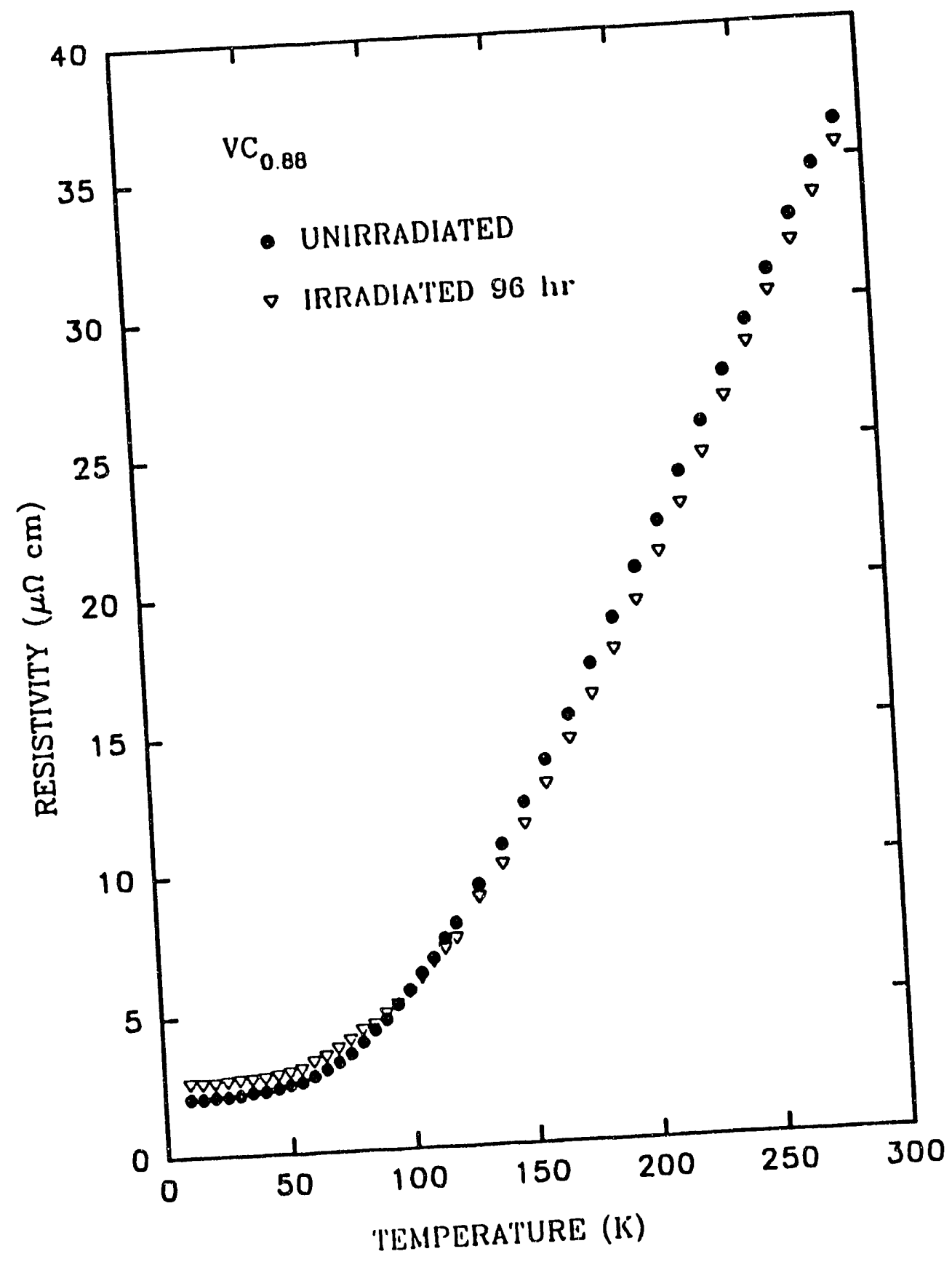




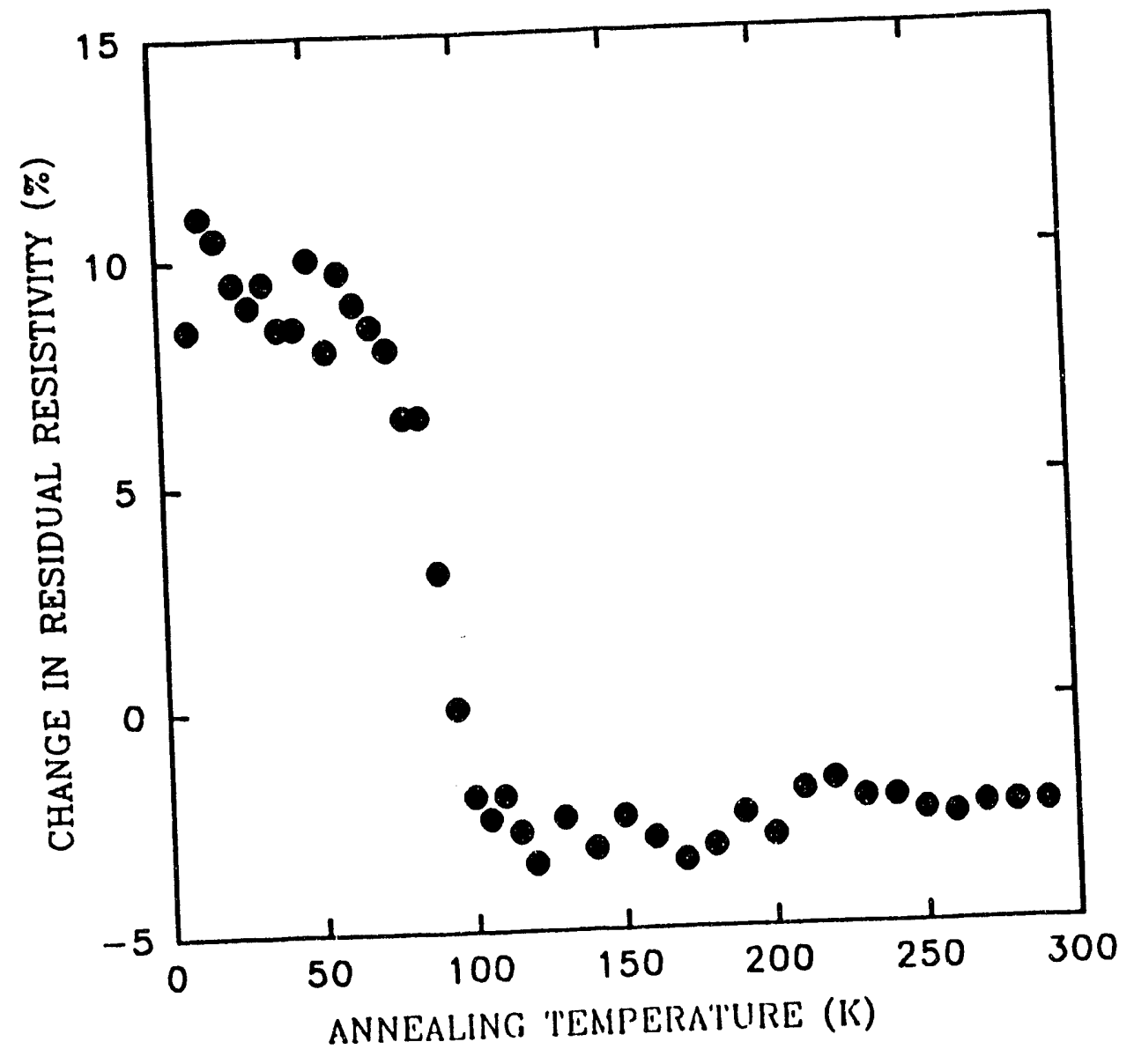




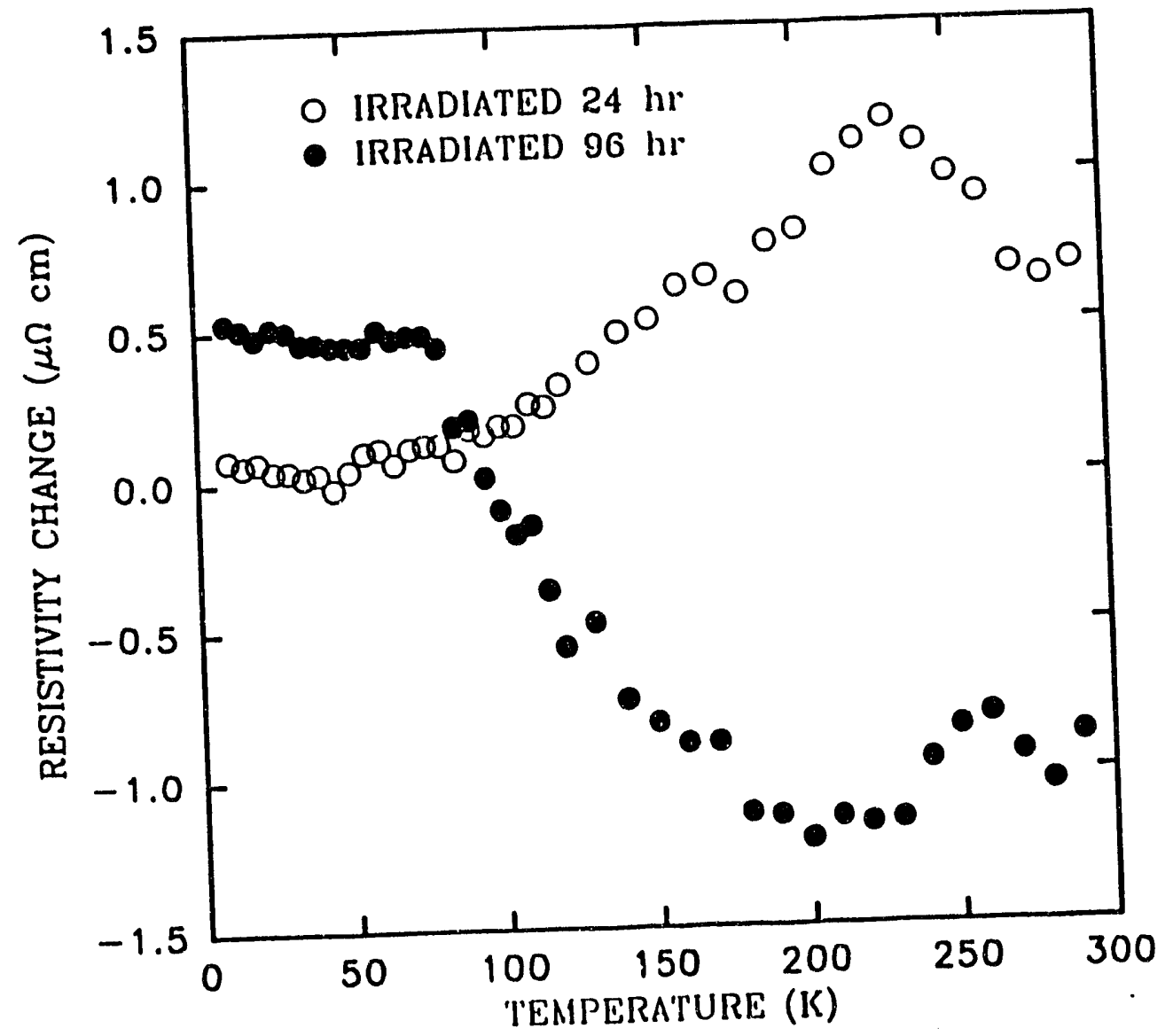




\section{PUBLICATIONS RESULTING FROM THIS PROJECT}

\section{Articles}

1. Electrical Properties of Transition-Metal Carbides of Group IV, F. A. Modine, M. D. Fogelle, C. B. Finch, and C. Y. Allison, Phys. Rev. B 40, 9558 (1989).

2. Effect of Low-Temperature Electron Iradiation on the Electrical Resistivity of $V C_{0.88}, \mathrm{H}$. J. John and G. Dixon (To be submitted to Phys. Rev. B).

3. Electrical Properties of Transition-Metal Carbides of Group V, C. Y. Allison, F. A. Modine, C. B. Finch, and M. D. Foegelle (To be submitted to Phys. Rev. B).

\section{Presentations}

Electrical Properties of the Group IV Transition Metal Carbides, F. A. Modine, M. D. Fogelle, C. B. Finch and C. Y. Allison, American Physical Society, St, Louis (1989).

Electrical Properties of the Group V Transition Metal Carbides, C. Y. Allison, F. A. Modine, M. D. Fogelle, and C. B. Finch, American Physical Society, St, Louis (1989).

Electrical Resistivity of $V C_{0.88}, \mathrm{H}$. J. John and C. Y. Allison, Mid West Solid State Conference, Rolla, MO (1989).

Effects of Electron Irradiations on the Electrical Resistivity of Vanadium Carbide, H. J. John and G. Dixon, American Physical Society, Cincinnati (1991). 


\section{Theses}

Effects of Electron Irradiation at Low Temperature on the Electrical Resistivity of Vanadium Carbide, H. J. John, M. S.

A copy of Article 1 has been submitted previously. Articles 2 and 3 will be submitted later. A copy of H. J. John's thesis is attached as Appendix. 

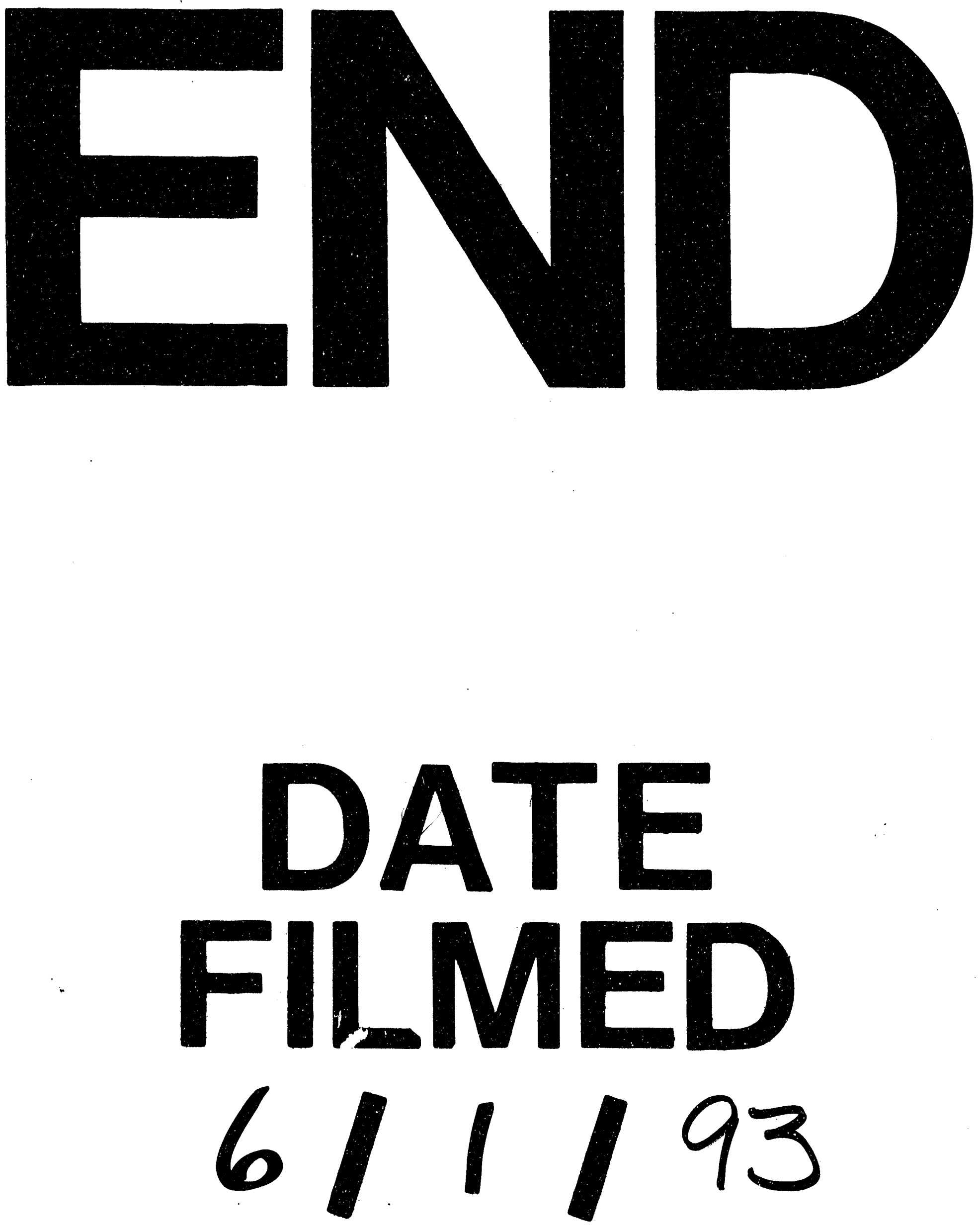
